\title{
BMJ Open Features for medically serious suicide attempters who do not have a strong intent to die: a cross-sectional study in rural China
}

\author{
Long Sun, ${ }^{1,2}$ Jie Zhang, ${ }^{1,3}$ Dorian A Lamis ${ }^{4}$
}

To cite: Sun L, Zhang J, Lamis DA. Features for medically serious suicide attempters who do not have a strong intent to die: a cross-sectional study in rural China. BMJ Open 2018;8:e023991. doi:10.1136/ bmjopen-2018-023991

- Prepublication history for this paper is available online. To view these files, please visit the journal online (http://dx.doi. org/10.1136/bmjopen-2018023991).

Received 5 May 2018

Revised 15 August 2018

Accepted 20 August 2018

Check for updates

(c) Author(s) (or their employer(s)) 2018. Re-use permitted under CC BY. Published by BMJ.

${ }^{1}$ Center for Suicide Prevention Research, School of Public Health, Shandong University, Jinan, China

${ }^{2}$ Key Laboratory of Health Economics and Policy Research, National Health Commission of China, Jinan, Shandong, China ${ }^{3}$ Department of Sociology, State University of New York Buffalo State, Buffalo, New York, USA ${ }^{4}$ Department of Psychiatry and Behavioral Sciences, Emory University School of Medicine, Atlanta, Georgia, USA

Correspondence to

Professor Jie Zhang; zhangj@buffalostate.edu

\section{ABSTRACT}

Objective Previous studies have implied that there were many Chinese suicide attempters who did not want to die by suicide. In the current study, we explored the factors which were associated with low levels of suicide intent. We also examined features for medically serious suicide attempters who do not have a strong intent to die in rural china.

Design Cross-sectional study.

Setting The interviews occurred between May 2012 and July 2013 in 13 rural counties in Shandong and Hunan provinces, China.

Participants Subjects were 791 medically serious suicide attempters whose injury and wounds were so serious they required hospitalisation or immediate medical care.

Results The results supported that less years of education $(\beta=-0.11, p=0.037)$, religious beliefs $(\beta=1.20, p=0.005)$, living alone $(\beta=1.92, p=0.017)$, negative life events $(\beta=0.29, p=0.003)$, low levels of impulsivity $(\beta=-0.10$, $p=0.013)$ and mental disorders $(\beta=2.82, p<0.001)$ were associated with higher levels of suicide intent.

Conclusion Results imply that there are some medically serious suicide attempters with a higher education and/ or exhibit impulsivity who do not want to die by suicide. These findings can inform practice to prevent suicide in rural China.

\section{BACKGROUND}

The WHO estimated that there were about 804000 suicide deaths worldwide in 2012 which equated to one person dying by suicide every $40 \mathrm{~s} .{ }^{1}$ With regard to suicide attempts, some have suggested that the number was about 20 times higher than suicide death, ${ }^{2}$ and nearly $50 \%$ of attempts required emergency medical treatment. ${ }^{34}$ China has one of the higher suicide rates in the world. ${ }^{5}$ Although the rates have decreased in recent years, suicide attempts and deaths are also important social and public health issues in China. ${ }^{6}$

In the last decades, several studies have explored the patterns of suicide and found differences between China and other
Strengths and limitations of this study

- This study is based on a large sample of suicide attempters in rural China $(n=791)$.

- Medically serious suicide attempters were consecutively recruited in selected emergency rooms which ensured the validity of the sample.

- This is one of few studies examining the factors associated with intent among medically serious suicide attempters in rural China.

- As this is a cross-sectional study, we cannot infer causal relationships among study variables.

- All of the attempters were interviewed following hospital discharge, so recall bias is a possibility.

countries. ${ }^{7}$ Many of these investigations imply that there are some suicide attempters who do not intend to die by suicide and may only instrumentally use for some other aims, such as getting attention from their family members, proving their viewpoint or behaviour.

First, there is a difference in percentages of mental disorders in suicide across countries. In Western countries, it has been estimated that $90 \%$ of individuals who die by suicide have a diagnosable mental disorder. ${ }^{8}$ However, this percentage was lower in comparison to Asian countries. For example, they were only about $40 \%-70 \%$ in mainland China, $16.2 \%$ in India and $12.0 \%$ in Malaysia. ${ }^{910}$ Although mental disorders remain an important risk factor for suicidal behaviour, other factors may play roles in Asian suicides. Thus, exploring the characteristics of suicide attempters in China not only may help us to understand the differences between China and Western countries, but also can provide important information about other Asian countries.

Second, impulsivity has been identified as another risk factor for suicide attempts both in China and Western countries. ${ }^{11} 12$ However, previous studies have found that 
approximately $50 \%$ of suicide attempters in China could be categorised as impulsive. ${ }^{13}$ It further implies that there is a large group of Chinese suicide attempters who do not really want to die by suicide, and their suicidal behaviours may be impulsive.

As mentioned above, many findings about Chinese suicide suggest that there are some suicidal individuals who do not really want to die by suicide. Suicide intent is defined as the level of intent to die by suicide, ${ }^{14}$ and many studies show that it is significantly associated with suicidal behaviour. ${ }^{15}$ Investigating suicide intent is helpful for us to better understand the suicide attempters who do not really want to die.

In recent years, many studies identified factors associated with suicide intent. In Western countries, researchers have found that older adults, ${ }^{16}$ rural residence, ${ }^{17}$ mental health problems ${ }^{18}$ and hopelessness ${ }^{19}$ were associated with suicide intent. In China, there were also some studies which supported that older age, higher level of education, living alone and suicide communication were correlated with higher level of suicide intent among individuals who died by suicide. ${ }^{20}{ }^{21}$ However, we have little knowledge about the suicide intent among suicide attempters who do not really want to die by suicide in China.

Thus, in the current study, we explored factors associated with low level of suicide intent. It was helpful for us to understand the features for medically serious suicide attempters who do not have a strong intent to die in rural China which may inform intervention and prevention strategies for at-risk individuals in rural China.

\section{METHODS}

\section{Study sample and the design}

In the current study, all of attempters were chosen from two provinces in China: Shandong and Hunan. Shandong is located in the north of China, and is a province with economic prosperity in both industry and agriculture. Hunan is located in the south of China, and is a province with economic prosperity in agriculture. In the two provinces, 13 rural counties were randomly selected.

In each of the rural county from May 2012 to July 2013, all hospital emergency departments were instructed to notify the research teams in each province when suicide attempts occurred. We consecutively recruited the attempters who were aged 15-54 years in either rural region. The enrolment of patients followed the definition of suicide attempt and deemed medically serious. In this study, suicide attempt was defined as someone who attempted suicide and wanted to die, but did not, ${ }^{22} 23$ and medically serious suicide attempters included those survivors whose injuries and wounds were so serious as to require hospitalisation or immediate medical care.

All of the interviewers received training about the study and were master or $\mathrm{PhD}$ level students in the medical school. The main aims of this training were to provide the interviewers with sufficient information about the study and questionnaire.

\section{Interviewing procedures}

All of the attempters were interviewed following hospital discharge. In order to successfully contact the attempters, all of them were first approached in-person by the local health agency and/or village administration. On their agreement of written informed consent, the interview time was scheduled approximately 2 months after suicide incident. Each attempter was interviewed separately by one trained interviewer in private at the village medical room or their home. For those participants who were too weak to talk, family members could assist in the interview by answering some of the questions on the protocol. The average time for each interview was 1.5 hours.

\section{Patient and public involvement statement}

The suicide attempters were first involved in the process of data collection. The aims of this study and outcome measures were informed via the interviewers. There are no plans to disseminate the qualitative study results to subjects or the relevant patient community.

\section{Measures}

Suicide intent

Beck's Suicidal Intent Scale (SIS) was used to measure the degree of suicide intent for the attempters. ${ }^{24}$ The SIS assesses attempters' precautions, planning, communication and expectations about the suicidal behaviour. There are 15 items on this scale, and each item is scored from 0 to 2. The psychometric properties of the English version of SIS has been evaluated among suicide attempters and decedents. ${ }^{25}$ The Chinese version of SIS also demonstrated sound reliability and validity which was shown in a previous study. ${ }^{26}$

\section{Social-demographic variables}

Age which ranged from 15 to 54 years was calculated to the time when the suicide occurred. Gender was measured by male or female. Education years were evaluated by the number of years in which the attempters completed in school. Married status was dichotomised as "never married' and 'ever married' with the latter including those who were divorced, separated or widowed. Occupation was assessed by peasant, businessman, public service staff, student, factory worker, rural doctor, teacher, housewife, unemployed and others. As most attempters were peasants, we recoded the variable into peasants and others. Religious belief was measured by what religion the attempters believed in, and the choices were Taoism, Muslim, Christianity, Buddhism, others and no religion. As there were few people who had a religious belief, the religious belief was recoded into 'yes' or 'no'.

\section{Living alone}

Living alone was assessed by a question that 'Do you live with others?' with response options being 'yes' or 'no'. Participants who did not live with others were deemed as living alone. The same evaluation method was used in our previous suicide studies. ${ }^{27}$ 


\section{Physical disease}

Physical disease was assessed by one question: 'Have you been diagnosed with a chronic disease now?' with response options including 'yes' or 'no'.

\section{Pesticide at home}

Pesticide availability at home was assessed with a single item which asked the participants if any type of farming chemicals were stored at home. The effect of pesticide on suicide has been shown in previous Chinese studies. ${ }^{28}$ The response options consisted of 'yes' or 'no'.

\section{Family suicide history}

Family suicide history was measured by a question: 'Do your family members conduct suicide behaviour before?' The answer also could be chosen from 'yes' or 'no'.

\section{Negative life events}

Negative life events (NLEs) were determined by the revised version of Interview for Recent Life Events (IRLE) ${ }^{29}$ The IRLE is a 64-item scale which measures life events occurring in the past 12 months. We also asked another question in case there were other life events which were not asked in the 64 items. The attempters could also answer if each event was perceived as positive or negative. In this study, we only used the number of NLEs. The Chinese version of IRLE has been used in previous suicide studies. ${ }^{30}$

\section{Impulsivity}

The 23-item Dickman Impulsivity Inventory (DII) was used to evaluate the level of impulsivity which was developed and validated in English. ${ }^{31}$ Each item included a response option of yes (1) or no (0). The sum score for all items was used in the data analysis, and the higher score represented a higher level of impulsivity. The Chinese version of the DII has been tested and demonstrated sound reliability and validity. ${ }^{32}$

\section{Coping skills}

Coping Responses Inventory (CRI) was used to assess the attempters' coping skills in this study. ${ }^{33}$ It asked the participants to evaluate the frequency $(0=$ never, $1=$ occasionally, $2=$ sometimes, $3=$ often) of engaging in 48 separate coping activities. Sample questions on the CRI included 'talk with your spouse or other relative about the problem' and 'think about how this event could change your life in a positive way'. The Chinese version of CRI had been used in previous suicide studies. ${ }^{34}$

\section{Mental disorder}

We used the Chinese version of the Structured Clinical Interview for the Diagnostic and Statistical Manual of Mental Disorders (SCID) ${ }^{35}$ to determine diagnoses for suicide attempters. Diagnoses were made by the psychiatrists with the written information obtained by the trained interviewers for each suicide attempt. There was one psychiatrist to make the diagnosis in each province. The Chinese version of the SCID was provided by the
Department of Psychiatry of Kaohsiung Medical College in Taiwan, ${ }^{36}$ and permission to use the work had been obtained. It also had been used in Chinese populations in many areas, including Taiwan, Hong Kong, Macau and mainland China for the past few decades. ${ }^{37}$ A total of 27 axis I mental diseases were detected by the SCID, and we used the dichotomous diagnosis for each of them with yes and no.

\section{Statistical methods}

IBM SPSS Statistics V.24.0 (Web Edition) was used for the data analysis. Student's t-tests or bivariable correlation analysis were used to compare the differences in suicide intent among categorical and continuous variables. Stepwise linear regression was conducted to examine the factors related to suicide intent. All of the tests were two-tailed, and a $\mathrm{p}$ value of $<0.05$ was considered statistically significant.

\section{RESULTS}

In the current study, 791 suicide attempters were successfully interviewed. Table 1 describes the sample distribution regarding social and psychological characteristics. The average age and education years were 31.63 and 6.90 , respectively. Among these attempters, there were more females $(63.0 \%)$ and peasants $(53.4 \%)$. The majority of attempters were ever married $(83.3 \%)$, did not believe in religion $(81.3 \%)$, did not suffer from a physical disease $(83.2 \%)$, stored pesticides at home $(60.4 \%)$, did not live alone $(95.6 \%)$, did not have a family history of suicide $(92.9 \%)$ or were diagnosed with a mental disorder $(80.9 \%)$. The mean for NLEs, impulsivity and coping skills were $1.83,9.89$ and 33.13 , respectively.

We also examined the differences in suicide intent among these social and psychological characteristics. Results demonstrated that age $(\mathrm{r}=0.071, \mathrm{p}=0.045)$, education years $(\mathrm{r}=-0.076, \mathrm{p}=0.032)$, religious belief $(\mathrm{t}=3.340$, $\mathrm{p}=0.001)$, living alone $(\mathrm{t}=2.315, \mathrm{p}=0.021)$, physical disease $(\mathrm{t}=2.416, \mathrm{p}=0.016)$, NLEs $(\mathrm{r}=0.148, \mathrm{p}=0.001)$, impulsivity $(\mathrm{r}=-0.084, \mathrm{p}=0.019)$ and mental disorder $(\mathrm{t}=7.393$, $\mathrm{p}=0.001$ ) were associated with suicide intent (see table 2).

Results of stepwise linear regression examining factors associated with suicide intent are presented in table 3 . We found that less education years $(\beta=-0.11, p=0.037)$, religious belief $(\beta=1.20, p=0.005)$, living alone $(\beta=1.92$, $\mathrm{p}=0.017)$, NLEs $(\beta=0.29, \mathrm{p}=0.003)$, low level of impulsivity $(\beta=-0.10, p=0.013)$, mental disorder $(\beta=2.82, p=0.001)$ were associated with higher levels of suicide intent.

\section{DISCUSSION}

The present study focused on suicide intent among medically serious suicide attempters in rural China. The primary purpose was to explore the features for medically serious suicide attempters who did not have a strong intent to die. Results indicated that the attempters with a strong intent to die were associated with religious belief, 
Table 1 Description of the social and psychological characteristics among Chinese rural medically serious suicide attempters $(n=791)$

\begin{tabular}{ll}
\hline Variables & Mean \pm SD/n (\%) \\
\hline Age & $31.63 \pm 8.00$ \\
\hline Gender & \\
\hline Male & $293(37.0)$ \\
\hline Female & $498(63.0)$ \\
\hline Education years & $6.90 \pm 3.26$ \\
\hline Married status & \\
\hline Never married & $132(16.7)$ \\
\hline Ever Married & $659(83.3)$ \\
\hline Occupation & \\
\hline Peasant & $422(53.4)$ \\
\hline Others & $369(46.6)$ \\
\hline Religious belief & \\
\hline Yes & $148(18.7)$ \\
\hline No & $643(81.3)$ \\
\hline Living alone & \\
\hline Yes & $35(4.4)$ \\
\hline No & $756(95.6)$ \\
\hline Physical disease & \\
\hline Yes & $133(16.8)$ \\
\hline No & $658(83.2)$ \\
\hline Pesticide at home & \\
\hline Yes & $478(60.4)$ \\
\hline No & $313(39.6)$ \\
\hline Family suicide history & \\
\hline Yes & $56(7.1)$ \\
\hline No & $735(92.9)$ \\
\hline Impulsivity & $1.83 \pm 1.77$ \\
\hline Mental disorder & $9.89 \pm 4.08$ \\
\hline No & $33.13 \pm 10.16$ \\
\hline
\end{tabular}

living alone, NLEs and mental disorder; whereas, the low intent suicide attempters had less years of education and more impulsivity.

We found that education years were negatively associated with suicide intent. It means that the attempters with higher education have lower intention to die by suicide behaviour. Many studies have identified that higher education is a protective factor for suicide behaviour worldwide. ${ }^{38}{ }^{39}$ In China, previous studies also support this relationship between education and suicide intent among rural suicides. ${ }^{40}$

Religious belief is another factor associated with strong suicide intent. As there are few people who have
Table 2 Comparing the suicide intent among the social and psychological characteristics $(n=791)$

\begin{tabular}{|c|c|c|c|}
\hline Variables & $\begin{array}{l}\text { Suicide intent } \\
\text { (mean } \pm S D)\end{array}$ & $t / r$ & $P$ values \\
\hline Age & - & 0.071 & 0.045 \\
\hline Gender & & 0.342 & 0.559 \\
\hline Male & $9.37 \pm 4.96$ & & \\
\hline Female & $9.86 \pm 4.84$ & & \\
\hline Education years & - & -0.076 & 0.032 \\
\hline Married status & & 1.179 & 0.239 \\
\hline Never married & $9.22 \pm 4.88$ & & \\
\hline Ever married & $9.77 \pm 4.89$ & & \\
\hline Occupation & & 1.811 & 0.071 \\
\hline Peasant & $9.97 \pm 4.92$ & & \\
\hline Others & $9.34 \pm 4.84$ & & \\
\hline Religious belief & & 3.430 & 0.001 \\
\hline Yes & $10.91 \pm 4.82$ & & \\
\hline No & $9.39 \pm 4.87$ & & \\
\hline Living alone & & 2.315 & 0.021 \\
\hline Yes & $11.54 \pm 5.52$ & & \\
\hline No & $9.59 \pm 4.85$ & & \\
\hline Physical disease & & 2.416 & 0.016 \\
\hline Yes & $10.61 \pm 4.93$ & & \\
\hline No & $9.49 \pm 4.86$ & & \\
\hline Pesticide at home & & -0.980 & 0.327 \\
\hline Yes & $9.54 \pm 4.66$ & & \\
\hline No & $9.89 \pm 5.23$ & & \\
\hline Family suicide history & & 2.104 & 0.036 \\
\hline Yes & $11.00 \pm 5.18$ & & \\
\hline No & $9.58 \pm 4.86$ & & \\
\hline Negative life events & - & 0.148 & 0.000 \\
\hline Impulsivity & - & -0.084 & 0.019 \\
\hline Coping skill & - & -0.067 & 0.061 \\
\hline Mental disorder & & 7.393 & 0.000 \\
\hline Yes & $12.24 \pm 4.77$ & & \\
\hline No & $9.07 \pm 4.72$ & & \\
\hline All & $9.68 \pm 4.89$ & - & - \\
\hline
\end{tabular}

a religious belief in China, ${ }^{41}$ many people see religious belief as a deviant behaviour. Suicide which also can be seen as a deviant behaviour in the society may be correlated between them. Besides, many Chinese rural residents believe in a religion after they suffer difficulties or misfortunes. Suffering difficulties or misfortunes, as an important risk factor for suicide, ${ }^{42}$ may promote the intent to die by suicide in rural China. This is why attempters with religious belief have strong intent to die by suicide. It is different from the findings in Western countries. ${ }^{43}$ 
Table 3 Linear regression about the social and psychological characteristics associated with suicide intent $(n=791)$

\begin{tabular}{lrrl}
\hline Variables & \multicolumn{1}{c}{$\boldsymbol{\beta}$} & \multicolumn{1}{c}{$\mathbf{9 5 \%} \mathbf{C l}$} & $\mathbf{P}$ values \\
\hline Education years & -0.11 & -0.21 to 0.01 & 0.037 \\
Religious belief & 1.20 & 0.36 to 2.04 & 0.005 \\
\hline Living alone & 1.92 & 0.34 to 3.51 & 0.017 \\
Negative life events & 0.29 & 0.10 to 0.48 & 0.003 \\
Impulsivity & -0.10 & -0.18 to 0.02 & 0.013 \\
\hline Mental disorder & 2.82 & 1.98 to 3.66 & 0.000 \\
\hline Constant & 10.04 & 8.91 to 11.16 & 0.000 \\
\hline
\end{tabular}

Adjust $\mathrm{R}^{2}=0.097$.

Stepwise linear regression was used in this regression.

We also found living alone and NLEs were associated with suicide intent among attempters. Both of them have been shown to be risk factors for suicide behaviour in previous studies worldwide. ${ }^{44}{ }^{45}$ People living alone often find it difficult to communicate with others which is a risk factor for suicide intent. ${ }^{46}$ Individuals who encounter NLEs often experience psychological problems which contribute to suicidal behaviour. In the same way, people who live alone and suffer NLEs may have a strong intent to die by suicide.

Impulsivity has been identified as an important risk factor for suicide in many studies. ${ }^{47} 48$ As we discussed above, many Chinese suicide attempters can be categorised as impulsive. ${ }^{13}$ One of the possible reasons may be that borderline personality disorder is associated with impulsivity and self-harm behaviour, but was not diagnosed in the current study. ${ }^{49}$ Previous studies have also suggested that impulsivity contributed to suicide death in rural China. ${ }^{21}$ It implies that some attempters do not want to die by suicide which is consistent with our assumption.

The present study also identified mental disorders as an important risk factor for suicidal behaviour. ${ }^{50-52} \mathrm{An}$ individual diagnosed with a mental disorder suffers from psychological symptoms which contribute to an increased risk for suicide. Thus, attempters with mental disorders may want to die more than those who do not have any mental disorder.

In the current study, we did not find gender differences in suicide intent among suicide attempters. Previous studies demonstrated that male attempters tend to choose violent and lethal methods. ${ }^{53}$ It was easy for us to conclude that males may experience higher levels of suicide intent. However, the choice of the suicide means may be caused by the higher level of violence for men compared with women, and we cannot conclude that men may have a higher intent to die. ${ }^{21}$ In the current study, we also examined the relationship between physical disease, family suicide history and suicide intent. Both of them were not associated with suicide intent. Physical disease was associated with suicidal behaviour which was supported by previous studies. ${ }^{54}$ However, physical disease did not have a stronger association with those identified with a stronger intent to die compared with those who did not have a strong intent to die. Previous studies have found that physical disease may lead to a mental disorder, increasing the likelihood for suicidal behaviour. ${ }^{55}$ Although some studies found family suicide history was associated with suicidal behaviour, ${ }^{56}$ we did not find any evidence showing this relation.

There were several limitations to our study which should be considered when interpreting these findings. First, as this is a cross-sectional study, we cannot infer any causal relationship for the study variables. Second, all of the attempters were interviewed following discharge from hospitals, so recall bias is a potential confounder. Third, the participants in this study were all medically serious suicide attempters, and the results may not be consistent with other types of suicide attempt. Finally, lethality, which is an important factor associated with suicide intent, was not investigated in our study.

\section{CONCLUSION}

Despite these limitations, this study contributes to our understanding of Chinese suicidal behaviour. Our results support that there are some medically serious suicide attempters with higher education and impulsivity who do not really want to die by suicide. These findings can inform suicide assessment and intervention to prevent suicide in China. ${ }^{57}$

Acknowledgements We would like to thank the participants in this study, and we also want to thank the research teams in China for their field work in the data collection.

Contributors LS analysed the data and wrote the manuscript, JZ designed the study and reviewed the paper and DAL reviewed and edited the manuscript.

Funding The research was supported by the US National Institute of Mental Health (R01 MH068560) and National Natural Science Foundation of China (71603149).

Competing interests None declared.

Patient consent Obtained.

Ethics approval The IRB approvals from both the Chinese institutions (Shandong University and Central North University) and the US-based university (State University of New York, Buffalo State) where the principal investigator is affiliated ensured the human subjects protection and the ethical methodology regulated by NIMH which funded the project.

Provenance and peer review Not commissioned; externally peer reviewed.

Data sharing statement The data and materials used in this study are available from the first author (LS) and corresponding author (JZ) on reasonable request.

Open access This is an open access article distributed in accordance with the Creative Commons Attribution 4.0 Unported (CC BY 4.0) license, which permits others to copy, redistribute, remix, transform and build upon this work for any purpose, provided the original work is properly cited, a link to the licence is given, and indication of whether changes were made. See: https://creativecommons.org/ licenses/by/4.0/.

\section{REFERENCES}

1. WHO. Preventing suicide: a global imperative. Geneva: World Health Organization, 2014.

2. Sun J, Guo X, Zhang J, et al. Incidence and fatality of serious suicide attempts in a predominantly rural population in Shandong, China: a public health surveillance study. BMJ Open 2015;5:e006762. 
3. Maris RW, Berman AL, Silverman MM. Comprehensive textbook of suicidology. New York: The Guilford Press, 2000.

4. Crosby AE, Han B, Ortega LA, et al. Suicidal thoughts and behaviors among adults aged $\geq 18$ years-United States, 2008-2009. MMWR Surveill Summ 2011;60:1-22.

5. Phillips MR, Li X, Zhang Y. Suicide rates in China, 1995-99. The Lancet 2002;359:835-40.

6. Zhang J, Sun L, Liu Y, et al. The change in suicide rates between 2002 and 2011 in China. Suicide Life Threat Behav 2014;44:560-8.

7. Qin P, Mortensen PB. Specific characteristics of suicide in China. Acta Psychiatr Scand 2001;103:117-21.

8. Cavanagh JT, Carson AJ, Sharpe M, et al. Psychological autopsy studies of suicide: a systematic review. Psychol Med 2003;33:395-405.

9. Zhang J, Xiao S, Zhou L. Mental disorders and suicide among young rural Chinese: a case-control psychological autopsy study. Am J Psychiatry 2010;167:773-81.

10. Choo CC, Harris KM, Chew PKH, et al. Does ethnicity matter in risk and protective factors for suicide attempts and suicide lethality? PLoS One 2017;12:e0175752.

11. Zhang J, Lin L. The moderating effects of impulsivity on Chinese rural young suicide. J Clin Psychol 2014;70:579-88.

12. Baca-Garcia E, Diaz-Sastre C, García Resa E, et al. Suicide attempts and impulsivity. Eur Arch Psychiatry Clin Neurosci 2005;255:152-6.

13. Li X, Phillips M, Wang $Y$, et al. The comparison of impulsive and nonimpulsive attempted suicide. Chinese J Nerv Men Dis 2003;29:27-31.

14. Freedenthal S. Assessing the wish to die: a 30-year review of the suicide intent scale. Arch Suicide Res 2008;12:277-98.

15. Scocco P, Marietta P, Tonietto M, et al. The role of psychopathology and suicidal intention in predicting suicide risk: a longitudinal study. Psychopathology 2000;33:143-50.

16. Miret M, Nuevo R, Morant C, et al. Differences between younger and older adults in the structure of suicidal intent and its correlates. Am J Geriatr Psychiatry 2010;18:839-47.

17. Krishna M, Rajendra R, Majgi SM, et al. Severity of suicidal intent, method and behaviour antecedent to an act of self-harm: a cross sectional study of survivors of self-harm referred to a tertiary hospital in Mysore, south India. Asian J Psychiatr 2014;12:134-9.

18. Mars B, Heron J, Crane $C$, et al. Differences in risk factors for selfharm with and without suicidal intent: findings from the ALSPAC cohort. J Affect Disord 2014;168:407-14.

19. Cheung YB, Law CK, Chan B, et al. Suicidal ideation and suicidal attempts in a population-based study of Chinese people: risk attributable to hopelessness, depression, and social factors. J Affect Disord 2006;90(2-3):193-9.

20. Zhou XM, Jia SH. Suicidal communication signifies suicidal intent in Chinese completed suicides. Soc Psychiatry Psychiatr Epidemiol 2012;47:1845-54.

21. Sun L, Zhang J. Characteristics of Chinese rural young suicides: who did not have a strong intent to die. Compr Psychiatry 2015;57:73-8.

22. Silverman MM, Berman AL, Sanddal ND, et al. Rebuilding the tower of Babel: a revised nomenclature for the study of suicide and suicidal behaviors. Part 1: Background, rationale, and methodology. Suicide Life Threat Behav 2007;37:248-63.

23. Silverman MM, Berman AL, Sanddal ND, et al. Rebuilding the tower of Babel: a revised nomenclature for the study of suicide and suicidal behaviors. Part 2: Suicide-related ideations, communications, and behaviors. Suicide Life Threat Behav 2007;37:264-77.

24. Beck AT, Schuyler D, Herman I. Development of suicidal intent scales. 249. Oxford, England: Charles Press Publishers, 1974.

25. Beck AT, Lester D. Components of suicidal intent in completed and attempted suicides. J Psychol 1976;92:35-8.

26. Zhang J, Jia C. Suicidal intent among young suicides in rural China. Arch Suicide Res 2011;15:127-39.

27. Zhang J, Sun L. Suicide ideation and acceptability among females aged 15 to 34 years in rural China. J Nerv Ment Dis 2014;202:161-6.

28. Zhang M, Fang X, Zhou L, et al. Pesticide poisoning in Zhejiang, China: a retrospective analysis of adult cases registration by occupational disease surveillance and reporting systems from 2006 to 2010. BMJ Open 2013;3:e003510.

29. Paykel ES, Prusoff BA, Uhlenhuth EH. Scaling of life events. Arch Gen Psychiatry 1971;25:340-7.

30. Sun L, Zhang J. Coping skill as a moderator between negative life events and suicide among young people in rural China. J Clin Psychol 2015;71:258-66.

31. Dickman SJ. Functional and dysfunctional impulsivity: personality and cognitive correlates. J Pers Soc Psychol 1990;58:95-102.
32. Gao Q, Zhang J, Jia C. Psychometric properties of the dickman impulsivity instrument in suicide victims and living controls of rural China. J Affect Disord 2011;132:368-74.

33. Moos RH, Brennan PL, Fondacaro MR, et al. Approach and avoidance coping responses among older problem and nonproblem drinkers. Psychol Aging 1990;5:31-40.

34. Sun L, Zhang J. Psychological strains and suicidal intent: an empirical study to relate the 2 Psychopathological Variables. J Nerv Ment Dis 2016;204:855-60.

35. Spitzer RL, Williams JBW, Gibbon M, et al. Instruction manual for the structured clinical interview for DSM-III-R (SCID, 6/1/88 Revision). New York: Biometrics Research Department, New York State Psychiatric Institute, 1988.

36. Gu J, Chen Y. Instruction manual for the structured clinical interview for DSM-III-R (Chinese Edition). Kaohsiung: Kaohsiung Medical College, Taiwan, 1993

37. Lyu J, Zhang J. Characteristics of schizophrenia suicides compared with suicides by other diagnosed psychiatric disorders and those without a psychiatric disorder. Schizophr Res 2014;155:59-65.

38. $\mathrm{Li} \mathrm{Y}, \mathrm{Li}$ Y, Cao J. Factors associated with suicidal behaviors in mainland China: a meta-analysis. BMC Public Health 2012;12:524-30.

39. Beautrais AL. Risk factors for suicide and attempted suicide among young people. Aust N Z J Psychiatry 2000;34:420-36.

40. Liu BP, Wang XT, Jia CX. Suicide attempters with high and low suicide intent: different populations in rural China. Psychiatry Res 2017;251:176-81.

41. Yang F. The red, black, and gray markets of religion in China. Sociol Q 2006:47:93-122.

42. Jaiswal SV, Faye AD, Gore SP, et al. Stressful life events, hopelessness, and suicidal intent in patients admitted with attempted suicide in a tertiary care general hospital. J Postgrad Med 2016;62:102-4.

43. Stack S, Kposowa AJ. Religion and suicide acceptability: a crossnational analysis. J Sci Study Relig 2011;50:289-306.

44. Bao WN, Haas A, Pi Y. Life strain, negative emotions, and delinquency: An empirical test of general strain theory in the People's Republic of China. Int J Offender Ther Comp Criminol 2004;48:281-97.

45. Kinyanda E, Hjelmeland $H$, Musisi S. Negative life events associated with deliberate self-harm in an African population in Uganda. Crisis 2005;26:4-11.

46. Pompili M, Belvederi Murri M, Patti S, et al. The communication of suicidal intentions: a meta-analysis. Psychol Med 2016;46:2239-53.

47. Braquehais MD, Oquendo MA, Baca-García E, et al. Is impulsivity a link between childhood abuse and suicide? Compr Psychiatry 2010;51:121-9.

48. Swann AC, Dougherty DM, Pazzaglia PJ, et al. Increased impulsivity associated with severity of suicide attempt history in patients with bipolar disorder. Am J Psychiatry 2005;162:1680-7.

49. Choo C, Diederich J, Song I, et al. Cluster analysis reveals risk factors for repeated suicide attempts in a multi-ethnic Asian population. Asian J Psychiatr 2014;8:38-42.

50. Bi B, Tong J, Liu L, et al. Comparison of patients with and without mental disorders treated for suicide attempts in the emergency departments of four general hospitals in Shenyang, China. Gen Hosp Psychiatry 2010;32:549-55.

51. Beautrais AL, Joyce PR, Mulder RT, et al. Prevalence and comorbidity of mental disorders in persons making serious suicide attempts: a case-control study. Am J Psychiatry 1996;153:1009-14.

52. Xu H, Qin L, Wang J, et al. A cross-sectional study on risk factors and their interactions with suicidal ideation among the elderly in rural communities of Hunan, China. BMJ Open 2016;6:e010914.

53. Choo CC, Harris KM, Ho RC. Prediction of lethality in suicide attempts: gender matters. Omega 2017.

54. Timonen M, Viilo K, Väisänen $\mathrm{E}$, et al. Burden of illness and suicide in elderly people. Physical disease and depression are prevalent in elderly Finnish suicide victims. BMJ 2002;325:441.

55. Ge D, Sun L, Zhou C, et al. Exploring the risk factors of suicidal ideation among the seniors in Shandong, China: A path analysis. $J$ Affect Disord 2017;207:393-7.

56. Bridge JA, Reynolds B, McBee-Strayer SM, et al. Impulsive aggression, delay discounting, and adolescent suicide attempts: effects of current psychotropic medication use and family history of suicidal behavior. J Child Adolesc Psychopharmacol 2015;25:114-23.

57. Harris KM, Syu JJ, Lello OD, et al. The ABC's of Suicide risk assessment: applying a tripartite approach to individual evaluations. PLoS One 2015;10:e0127442. 